\title{
Behavioral Sciences
}

National Cancer Institute

\section{Source}

National Cancer Institute. Behavioral Sciences. NCl Thesaurus. Code C16328.

The scientific disciplines concerned with the analysis and investigation of human and animal behavior through observation and scientific experimentation. 